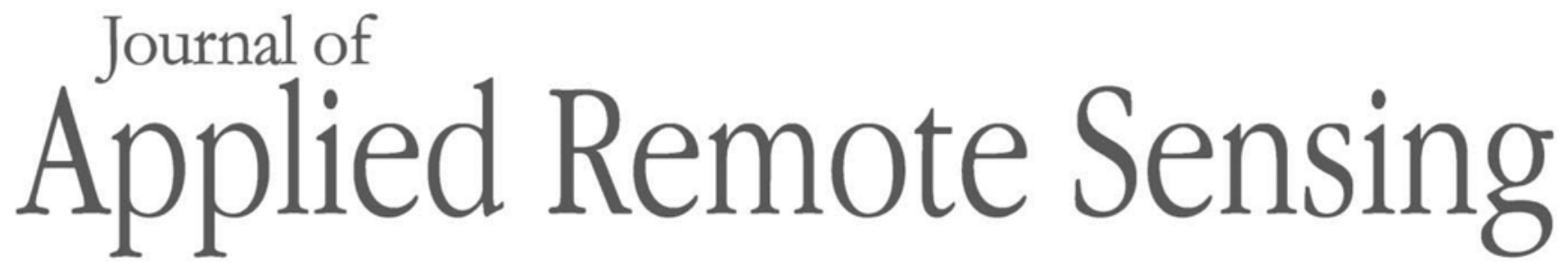

RemoteSensing.SPIEDigitalLibrary.org

\title{
Remote sensing analysis of vegetation at the San Carlos Apache Reservation, Arizona and surrounding area
}

\author{
Laura M. Norman \\ Barry R. Middleton \\ Natalie R. Wilson
}




\title{
Remote sensing analysis of vegetation at the San Carlos Apache Reservation, Arizona and surrounding area
}

\author{
Laura M. Norman,* Barry R. Middleton, and Natalie R. Wilson \\ U.S. Geological Survey, Western Geographic Science Center, Tucson, \\ Arizona, United States
}

\begin{abstract}
Mapping of vegetation types is of great importance to the San Carlos Apache Tribe and their management of forestry and fire fuels. Various remote sensing techniques were applied to classify multitemporal Landsat 8 satellite data, vegetation index, and digital elevation model data. A multitiered unsupervised classification generated over 900 classes that were then recoded to one of the 16 generalized vegetation/land cover classes using the Southwest Regional Gap Analysis Project (SWReGAP) map as a guide. A supervised classification was also run using field data collected in the SWReGAP project and our field campaign. Field data were gathered and accuracy assessments were generated to compare outputs. Our hypothesis was that a resulting map would update and potentially improve upon the vegetation/land cover class distributions of the older SWReGAP map over the $24,000 \mathrm{~km}^{2}$ study area. The estimated overall accuracies ranged between $43 \%$ and $75 \%$, depending on which method and field dataset were used. The findings demonstrate the complexity of vegetation mapping, the importance of recent, highquality-field data, and the potential for misleading results when insufficient field data are collected. (C) The Authors. Published by SPIE under a Creative Commons Attribution 3.0 Unported License. Distribution or reproduction of this work in whole or in part requires full attribution of the original publication, including its DOI. [DOI: 10.1117/1.JRS.12.026017]
\end{abstract}

Keywords: vegetation mapping; remote sensing; southwest regional gap analysis project; Landsat 8 operational land imager.

Paper 180160 received Feb. 22, 2018; accepted for publication Apr. 18, 2018; published online May 15, 2018.

\section{Introduction}

Remote sensing technology is often used to document and classify existing vegetation data at the regional scales. ${ }^{1}$ Vegetation/land cover maps can be developed either at a community level or species level by discerning spectral characteristics and translating them into classes. ${ }^{2}$ Large-scale projects are often constrained by the limited availability of high-resolution imagery and depend on lower resolution remotely sensed imagery as inputs that create lower resolution outputs. ${ }^{3}$ Accuracy can increase when newer products are used and when lower resolution data can be validated with field data. ${ }^{4}$ Gathering baseline conditions and change monitoring are advantages when creating good maps and improving the quality of the results. ${ }^{5}$

A large mapping effort was undertaken to classify vegetation in the USA by the National Gap Analysis Program (GAP), where gap analysis was defined as a method for identifying "gaps" in conservation land and/or water locations. ${ }^{6}$ This was improved upon in the five southwestern states (Arizona, Colorado, New Mexico, Nevada, and Utah), by the Southwest Regional Gap Analysis Project (SWReGAP). SWReGAP provided land-cover mapping and assessment of biodiversity using Landsat ETM+ imagery (1999 to 2001) and digital elevation model (DEM) derivatives. ${ }^{7}$ The SWReGAP project used terrestrial ecological systems (TES) classification ${ }^{8}$ developed by NatureServe ${ }^{9}$ to emphasize dominant vegetation types. ${ }^{7,10,11}$ The SWReGAP map contains 125 land-cover classes with validation accuracy of $61 \% .^{7}$ This validation accuracy was based on an intermediate product, whereas the final, published map (based on all of the field observation

*Address all correspondence to: Laura M. Norman, E-mail: lnorman@usgs.gov 
sites with determined vegetation/land cover class) should be higher. In addition, the process of generalizing the vegetation/land cover classes for this study should result in a more accurate product as fewer, more generalized classes can be easier to map. Therefore, we felt that the SWReGAP map would be acceptable for use in this project.

Landsat Earth Observation Satellites have been collecting space-based imagery of the Earth's surface since 1972. ${ }^{12}$ The Landsat 8 satellite was launched in February 2013, with Operational Land Imager (OLI) and Thermal Infrared Sensor (TIRS) instruments onboard. OLI collects data with a spatial resolution of $30 \mathrm{~m}$ in the visible, near-IR, and SWIR wavelength regions, and a $15-\mathrm{m}$ panchromatic band. ${ }^{12}$ The OLI payload is distinguished for examining vegetative cover types. ${ }^{13-15}$

Land managers of the San Carlos Apache Tribe identified a need to obtain an updated vegetation map for better management of forest, woodland, and rangelands. The U.S. Geological Survey (USGS) Western Geographic Science Center (WGSC) used remotely sensed data to help the Tribe map rangeland condition. That map was later used to identify areas for spraying pesticides for invasive grasshoppers. ${ }^{16}$ In 2017, WGSC attempted a unique mapping approach to provide a more current vegetation map, both on and off the reservation, for the Tribe. The SWReGAP vegetation map was used as a starting point for this mapping effort.

Our hypothesis was that using the SWReGAP map as a base, and adding more recent multitemporal Landsat 8 OLI satellite data, along with vegetation index and DEM data, the SWReGAP map could be improved upon for a relatively small area $\left(24,000 \mathrm{~km}^{2}\right)$. It was postulated that using unsupervised algorithms to split the current multitemporal 30-m satellite data up into many classes, and recombining them using the SWReGAP map as a guide, an updated map, with improved accuracy, could be produced. It was also decided to pursue an initial supervised classification using field data from the SWReGAP and our field campaign. This paper presents an overview of how remotely sensed imagery was used to classify and map vegetation at the San Carlos Apache Reservation, Arizona and surrounding area, while also providing a discussion of its accuracy for the remote sensing of vegetation community.

\subsection{Study Area}

The San Carlos Apache Reservation in east-central Arizona, covers $7502 \mathrm{~km}^{2}$ and is the 10th largest reservation in the United States by land area, with a population of $10,709 .{ }^{17}$ The study area and map includes $16,500 \mathrm{~km}^{2}$ of adjacent land creating a larger area of interest (AOI; Fig. 1). Surrounding lands include White Mountain Apache Reservation, National Forests (Tonto, Apache-Sitgreaves, and Coronado), Bureau of Land Management, state, and private lands. Elevations range from $\sim 530 \mathrm{~m}$ along the Gila River to $3480 \mathrm{~m}$ on Mount Baldy in the White Mountains. On the San Carlos Apache Reservation, vegetation types including Ponderosa Pine Forests, Pinyon-Juniper Woodlands, grasslands, and desert scrub have significant ecological, cultural, and economic value for the Tribe that extends beyond the tribal lands and across the western United States. ${ }^{18,19}$

\section{Methods}

\subsection{Classification}

SWReGAP mapped 46 discrete classes in the study area; however, the Tribe did not require the specificity of the SWReGAP classes. Based on discussions with the San Carlos Apache Tribe (tribal ethnobotanist), ${ }^{20} 12$ classes were determined to be of interest. Two classes were added to identify areas that do not occur on the reservation but occur in the surrounding mapping area ("mine" land cover class and "Montane Grassland" vegetation type). Finally, two classes were added to be more in-line with the SWReGAP vegetation classes ("Madrean Pine-Oak Forest/ Woodland" and "Mesquite Upland Scrub"), as these common study area vegetation classes did not fit well into the original 12-class classification. This resulted in 16 classes for our analysis. To compare these classes with SWReGAP, a cross walk was developed between the generalized 


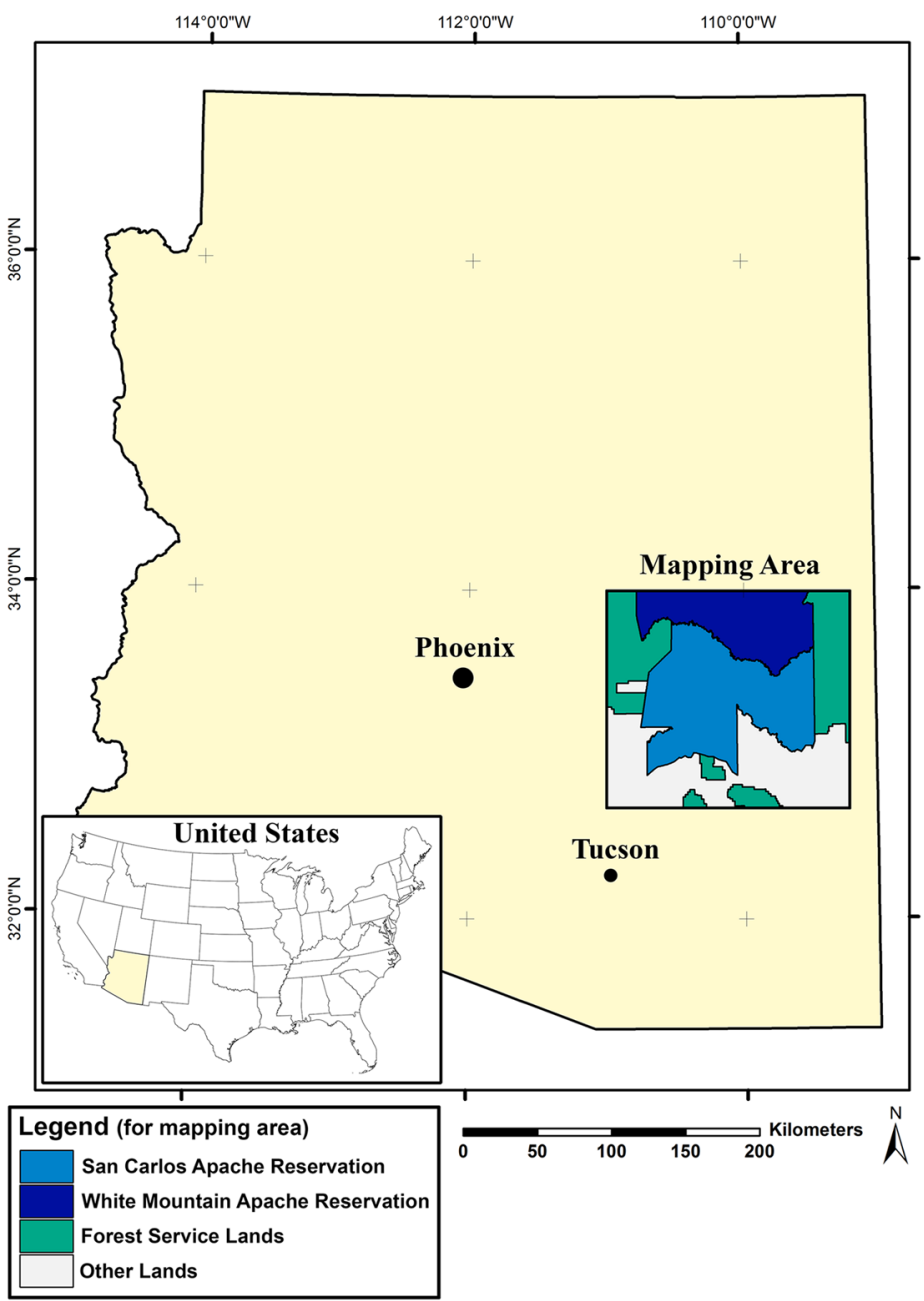

Fig. 1 Location of the study area in eastern Arizona, USA.

vegetation classes used in the unsupervised classification mapping effort and the more specific classes employed by SWReGAP for this mapping area (Table 1).

Of the 46 discrete classes that SWReGAP mapped in the study area, only a relatively small portion of them came up as what were considered, "likely" vegetation types in this analysis. We define "likely" vegetation types as the top three SWReGAP vegetation/land cover classes (nongeneralized) with the most pixels in common with the unsupervised class in question. In other words, the vegetation/land cover classes that best represented the unsupervised class, measured by the number of pixels sharing a common location. Many of the smaller classes, covering a low percentage of the mapping area $(\sim<0.5 \%)$, did not fit in this category. Additionally, some vegetation classes were grouped together into a single class (i.e., Dry-Mesic Mixed Conifer, Mesic Mixed Conifer, etc.) for the study.

\subsection{Remote Sensing}

A suite of Landsat 8 OLI images from 2014 to 2013 was used in the classification. These images are virtually cloud-free over the study area and are calibrated to surface reflectance; they were downloaded in February 2017 from the USGS earth resources observation and science (EROS) science processing architecture (ESPA) website ${ }^{21}$ and are from two Landsat path/rows, P35R37 and P36R37.

A high number of Landsat 8 dates were used to accurately represent the phenology of the vegetation and therefore better differentiate the vegetation classes. The following dates were selected: P35R37: September 24, 2013; March 19, 2014; May 6, 2014; June 7, 2014; 
October 13, 2014; and October 29, 2014 (six dates) and P36R37: July 29, 2013; February 22, 2014; May 13, 2014; June 30, 2014; September 2, 2014; October 4, 2014; and November 5, 2014 (seven dates). The Landsat 8 OLI surface reflectance data (bands 1 to 7) were subset to the study area coordinates. See Table 2 for information on selected bands.

Table 1 Cross walk between the unsupervised classification map and the SWReGAP map vegetation/land cover classes.

\begin{tabular}{|c|c|}
\hline $\begin{array}{l}\text { Unsupervised classification map } \\
\text { vegetation/land cover class }\end{array}$ & Associated SWReGAP vegetation/land cover class(es) \\
\hline Water & Open water \\
\hline Agriculture & Agriculture \\
\hline Riparian Forest/Woodland & $\begin{array}{l}\text { Rocky Mountain Lower Montane Riparian Woodland and Shrubland, } \\
\text { North American Warm Desert Lower Montane Riparian Woodland and } \\
\text { Shrubland, North American Warm Desert Riparian Woodland and } \\
\text { Shrubland, North American Warm Desert Riparian Mesquite Bosque, } \\
\text { Invasive Southwest Riparian Woodland and Shrubland }\end{array}$ \\
\hline Aspen Forest & Rocky Mountain Aspen Forest and Woodland \\
\hline Spruce-Fir Forest & $\begin{array}{l}\text { Rocky Mountain Subalpine Dry-Mesic Spruce-Fir Forest and } \\
\text { Woodland, Rocky Mountain Subalpine Mesic Spruce-Fir } \\
\text { Forest and Woodland }\end{array}$ \\
\hline Mixed Conifer Forest & $\begin{array}{l}\text { Rocky Mountain Montane Dry-Mesic Mixed Conifer Forest and } \\
\text { Woodland, Rocky Mountain Montane Mesic Mixed Conifer } \\
\text { Forest and Woodland }\end{array}$ \\
\hline Ponderosa Pine Forest & Rocky Mountain Ponderosa Pine Woodland \\
\hline $\begin{array}{l}\text { Madrean Pine-Oak } \\
\text { Forest/Woodland }\end{array}$ & Madrean Pine-Oak Forest and Woodland \\
\hline $\begin{array}{l}\text { Pinyon-Juniper-Evergreen } \\
\text { Oak Woodland }\end{array}$ & $\begin{array}{l}\text { Colorado Plateau Pinyon-Juniper Woodland, Madrean Encinal, } \\
\text { Inter-Mountain Basins Juniper Savanna, Madrean Pinyon-Juniper } \\
\text { Woodland, Madrean Juniper Savanna }\end{array}$ \\
\hline Interior chaparral & $\begin{array}{l}\text { Rocky Mountain Gambel Oak-Mixed Montane Shrubland, } \\
\text { Mogollon Chaparral }\end{array}$ \\
\hline Montane Grassland & Southern Rocky Mountain Montane-Subalpine Grassland \\
\hline $\begin{array}{l}\text { Plains and Semidesert } \\
\text { Grassland }\end{array}$ & $\begin{array}{l}\text { Apacherian-Chihuahuan Piedmont Semidesert Grassland and } \\
\text { Steppe, Inter-Mountain Basins Semidesert Shrub Steppe, } \\
\text { Inter-Mountain Basins Semidesert Grassland, Chihuahuan } \\
\text { Sandy Plains Semi-Desert Grassland }\end{array}$ \\
\hline Mesquite Upland Scrub & $\begin{array}{l}\text { Apacherian-Chihuahuan Mesquite Upland Scrub, Chihuahuan } \\
\text { Stabilized Coppice Dune and Sand Flat Scrub }\end{array}$ \\
\hline $\begin{array}{l}\text { Sonoran and Chihuahuan } \\
\text { Desertscrub }\end{array}$ & $\begin{array}{l}\text { North American Warm Desert Bedrock Cliff and Outcrop, North } \\
\text { American Warm Desert Volcanic Rockland, North American Warm } \\
\text { Desert Wash, North American Warm Desert Pavement, } \\
\text { Chihuahuan Succulent Desert Scrub, Chihuahuan Creosotebush, } \\
\text { Mixed Desert and Thorn Scrub, Sonoran Paloverde-Mixed Cacti } \\
\text { Desert Scrub, Sonora-Mojave Creosotebush-White Bursage Desert } \\
\text { Scrub, Chihuahuan Mixed Salt Desert Scrub, Sonoran } \\
\text { Mid-Elevation Desert Scrub }\end{array}$ \\
\hline Mine & Recently mined or quarried \\
\hline Urban & $\begin{array}{l}\text { Developed, open space-low intensity, developed, } \\
\text { medium—high intensity }\end{array}$ \\
\hline Unclassified & $\begin{array}{l}\text { Rocky Mountain Cliff and Canyon, Colorado Plateau Mixed Bedrock } \\
\text { Canyon and Tableland, Rocky Mountain Subalpine-Montane } \\
\text { Limber-Bristlecone Pine Woodland, North American Arid West } \\
\text { Emergent Marsh, Recently Burned }\end{array}$ \\
\hline
\end{tabular}


Table 2 Landsat 8 OLI band information for bands used in this analysis. ${ }^{22}$

\begin{tabular}{lcc}
\hline \hline Band name & Wavelength (micrometers) & Band number \\
\hline "Ultra" blue & 0.435 to 0.451 & 1 \\
Blue & 0.452 to 0.512 & 2 \\
Green & 0.533 to 0.590 & 3 \\
Red & 0.636 to 0.673 & 5 \\
NIR & 0.851 to 0.879 & 6 \\
Shortwave infrared 1 (SWIR1) & 1.566 to 1.651 & 7 \\
Shortwave infrared 2 (SWIR2) & 2.107 to 2.294 & 5 \\
\hline \hline
\end{tabular}

\subsubsection{Normalized difference vegetation index}

The normalized difference vegetation index (NDVI) is an index derived from reflectance values of the red and near-infrared (NIR) regions of the electromagnetic spectrum [Eq. (1)] and is sensitive to various biophysical vegetation characteristics, such as biomass and percent cover ${ }^{23-25}$

$$
\mathrm{NDVI}=(\mathrm{NIR}-\mathrm{Red}) /(\mathrm{NIR}+\mathrm{Red}) .
$$

NDVI was calculated for each of the 13 Landsat 8 scenes and used as inputs to the classification. For Landsat 8, the bands used in NDVI are b4 (red) and b5 (NIR). NDVI values range from -1 to 1 ; nonland surfaces (such as water and snow) typically assume negative values and land surfaces typically assume positive values. As landscapes become more densely vegetated, the NDVI trends to $1 .^{11,15,26}$

\subsubsection{Creating layer stacks for different elevation zones}

Vegetation communities are generally constrained by elevation gradients and the inclusion of elevation data can greatly increase the accuracy of mapping efforts. ${ }^{27}$ A $10-\mathrm{m}$ raster DEM from The National Map ${ }^{28}$ was downloaded, mosaiced, and reprojected (UTM, zone 12, WGS84) using bilinear interpolation, converted into units of feet, degraded in resolution to $30 \mathrm{~m}$, and finally subset to the study area coordinates. The newer $10-\mathrm{m}$ data were used as it is an updated version of the $30 \mathrm{~m}$ that corrects for some of the issues with the original 30-m data, such as edge matching/seam issues, while maintaining the potential of being updated from other high-resolution sources (such as LIDAR). A mask was created from the DEM data for elevations above and below $2591 \mathrm{~m}$. Snow contamination affecting the pixels of several image dates in areas above $2591 \mathrm{~m}$ was the main reason for splitting the scene using this elevation. Masking scenes using this threshold allowed more dates to be utilized in areas below this elevation because snow contamination in upland areas would have caused some otherwise excellent scenes to be rejected.

Initially, two layer stacks were produced, one for each Landsat path/row. The layer stack for P36/R37 consisted of bands 1 to 7 and NDVI for each of the seven dates followed by the DEM image to create a 57 band image. The layer stack for P35/R37 consisted of bands 1 to 7 and NDVI for each of the six dates, followed by the DEM image to create a 49 band image. The P35R37 layer stack was further split into two separate image stacks, one masked to elevations above $2591 \mathrm{~m}$, and one below that elevation. Only P35R37 contained elevations above this threshold in the study area.

For areas above 2591-m elevation, only four of the six dates were uncontaminated by snow cover; these four scenes and their derived NDVIs and DEM imagery were used to create a new 33 band layer stack for analysis in the high elevation zone. The Landsat path/row boundaries cut diagonally across the study area which resulted in strips of "extraneous" pixels as the individual image bands did not exactly cover the same area. To address this, all the individual image bands 
in two of the layer stacks affected by this issue (P35R37 below $2591 \mathrm{~m}$ and P36R37) were made into a binary mask with 0 representing no data and 1 representing usable image data. The minimum overlap area (intersection of polygons) was then determined and used to mask out the areas of the layer stack that contained any "no data" values. In summary, three layer stacks were made as follows:

i. (P35/R37) above $2591 \mathrm{~m}$-four dates (dates are September 24, 2013; June 7, 2014; October 13, 2014; and October 29, 2014) (33 band);

ii. (P35/R37) below $2591 \mathrm{~m}$-six dates (dates are September 24, 2013; March 19, 2014; May 6, 2014; June 7, 2014; October 13, 2014; and October 29, 2014) (49 band); and

iii. (P36R37) — seven dates (dates are July 29, 2013; February 22, 2014; May 13, 2014; June 30, 2014; September 2, 2014; October 4, 2014; and November 5, 2014) (57 band).

\subsubsection{Unsupervised classification}

Unsupervised classifications do not require training data like supervised classification and therefore may be more economical in developing land cover maps for large areas. We explored a unique method using iterations of unsupervised classifications and thematic class matching in an attempt to increase the accuracy of the classification.

For portions of the map above $2591 \mathrm{~m}$, a four-date layer stack (with corresponding NDVIs and DEM) was classified to initially create 10 unsupervised classes. Each of those 10 classes were then subset from the same layer stack and further classified into 10 additional classes, resulting in a total of 100 classes. One second-generation class was further subdivided into five classes, so 104 classes in total were created. Below $2591 \mathrm{~m}$ (P35R37), a six-date layer stack (with corresponding NDVIs and DEM) was classified to create 20 unsupervised classes. Each of those 20 classes were further subdivided into 20 additional classes for a total of 400 classes. For P36R37, a seven-date layer stack (with corresponding NDVIs and DEM) was iteratively classified $(20 \times 20)$ to ultimately create 400 unsupervised classes as well. The portion of the mapping area above $2591 \mathrm{~m}$ (only in P35R37) was far less than the portion of the image below this elevation, and needed far fewer classes to map.

The ERDAS Imagine (ver. 2014), ISODATA algorithm was used for the unsupervised classifications, and these multiple tiered classifications ultimately resulted in over 900 classes. For each ISODATA run, the parameters were set as follows: initialize from statistics; \# of classes from: $\mathrm{xx}$ to $\mathrm{xx}$ (i.e., from 20 to 20); minimum size (\%): 0.001; maximum SD: 3.00; minimum distance: 4.00; max. merges: 1; initialize means along: principle axis; scaling range: automatic; maximum iterations: 100; convergence threshold: 0.999; skip factors: $X: 1 Y: 1$; and classify zeros $=$ not checked.

\subsubsection{Vegetation class assignment}

To determine the most likely vegetation class of each of the 904 resultant unsupervised classes, they were compared with the original SWReGAP map. Each class was spatially subset from the SWReGAP map, and the top three SWReGAP vegetation class designations were determined for each unsupervised class. If the "top" SWReGAP class, determined by the number of pixels representing that class, was exceeded by summing the second and third place most likely SWReGAP classes, and these classes were to be grouped into a single class (i.e., Dry-Mesic Spruce-Fir, Mesic Spruce-Fir, etc.), the grouped class designation (i.e., Spruce-Fir, etc.) was now considered the most likely vegetation class. In other words, if the second and third place classes were to be grouped into a single class, and the number of pixels representing these summed classes exceeded the original first place selection, it was determined to be the most likely class. See Fig. 2 for further clarification.

After assigning the most likely class to all the unsupervised classes for P35R37, the Ponderosa and Mixed Conifer classes, that straddled the "border" across the 2591-m elevation threshold, were subset out, combined and reclassified (into 30 unsupervised classes) using the same four-date layer stack used for high elevations. Vegetation classes were then assigned using the technique described previously. This resulted in a much "cleaner transition" across this artificial elevation boundary. After the class assignments were made, the below and above 2591-m 


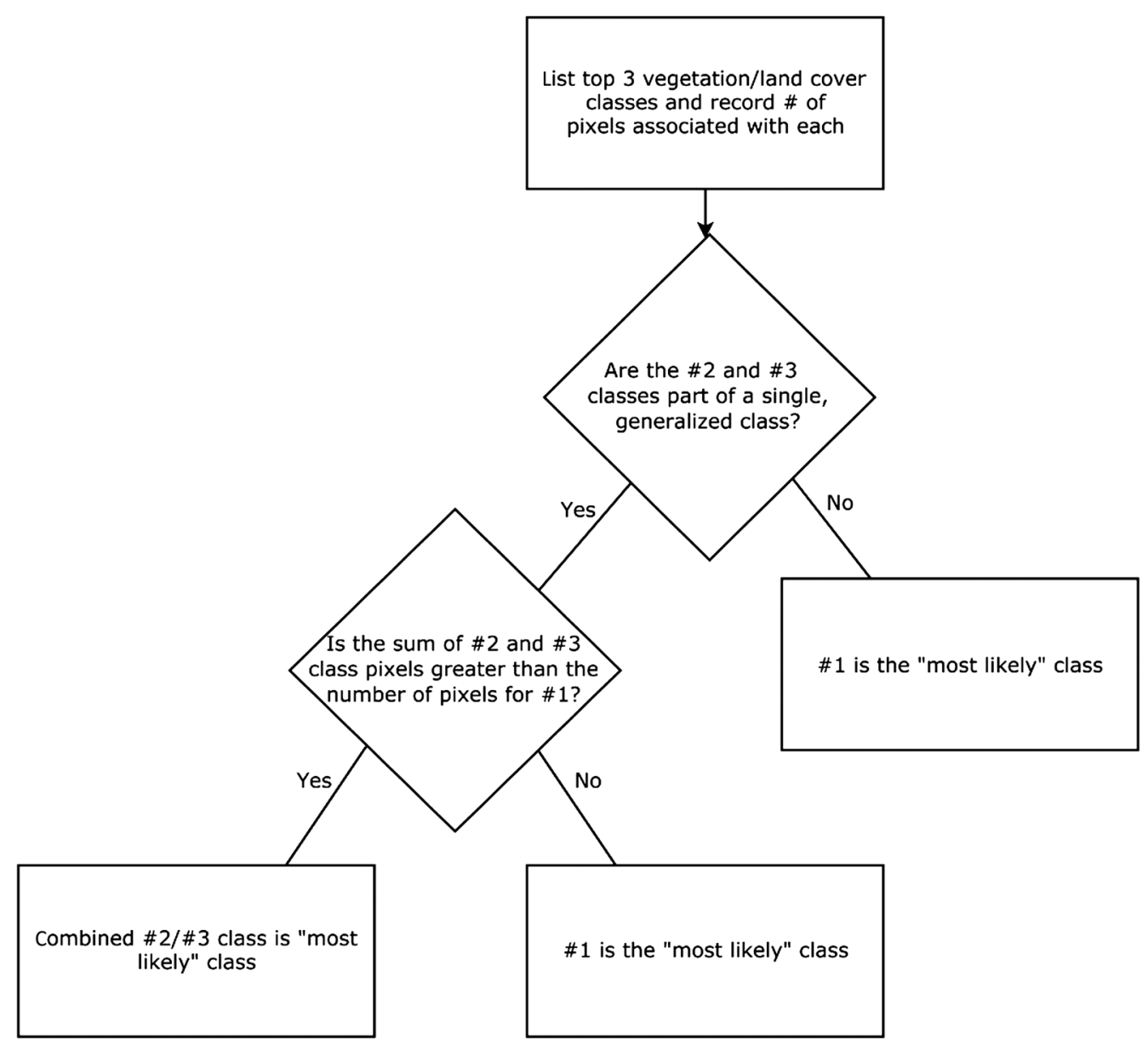

Fig. 2 Flowchart of process to determine "most likely" vegetation/land cover class.

portions of P35R37 were initially mosaiced together. This was followed by mosaicing (using the overlay function) the classified area that straddled the elevation threshold "over" the original P35R37 mosaic. The resultant P35R37 mosaic was then mosaiced (using the overlay function) "over" the classified P36R37 section of the mapping area. This resulted in roughly the eastern two-thirds of the mapping area being derived from P35R37 imagery, and the remaining western portion being generated from P36R37 imagery. Finally, a $3 \times 3$ pixel majority filter was applied to eliminate single pixels and small pixel groups that are potential "noise" in the image. Urban area boundary shapefiles from 2016 were then downloaded from the census website, ${ }^{29}$ screen digitized, and added to the map to create an urban class. See Fig. 3 for flowchart of process discussed above.

For use in accuracy assessment, the SWReGAP vegetation/land cover map was collapsed and recoded from its original 46 classes found in the study area to the final 16 classes used in the unsupervised classification map using the cross walk shown in Table 1. Classes that did not directly translate from the SWReGAP map to a more generalized class of the unsupervised classification map (i.e., recently burned, etc.) were labeled as "unclassified" on this map. None of the "unclassified" group of vegetation/land cover classes came up as a "likely" class in the analysis.

\subsubsection{Supervised classification}

A supervised classification was developed to compare with the unsupervised classification. An initial supervised classification was performed using all the field data [specifically vegetation/ land cover class and associated global positioning system (GPS) position] in the study area from the 2001 to 2004 SWReGAP and the 2017 field campaign as training sites (1028 points/pixels in all). No attempt was made to verify that the SWReGAP points were indeed still the same 


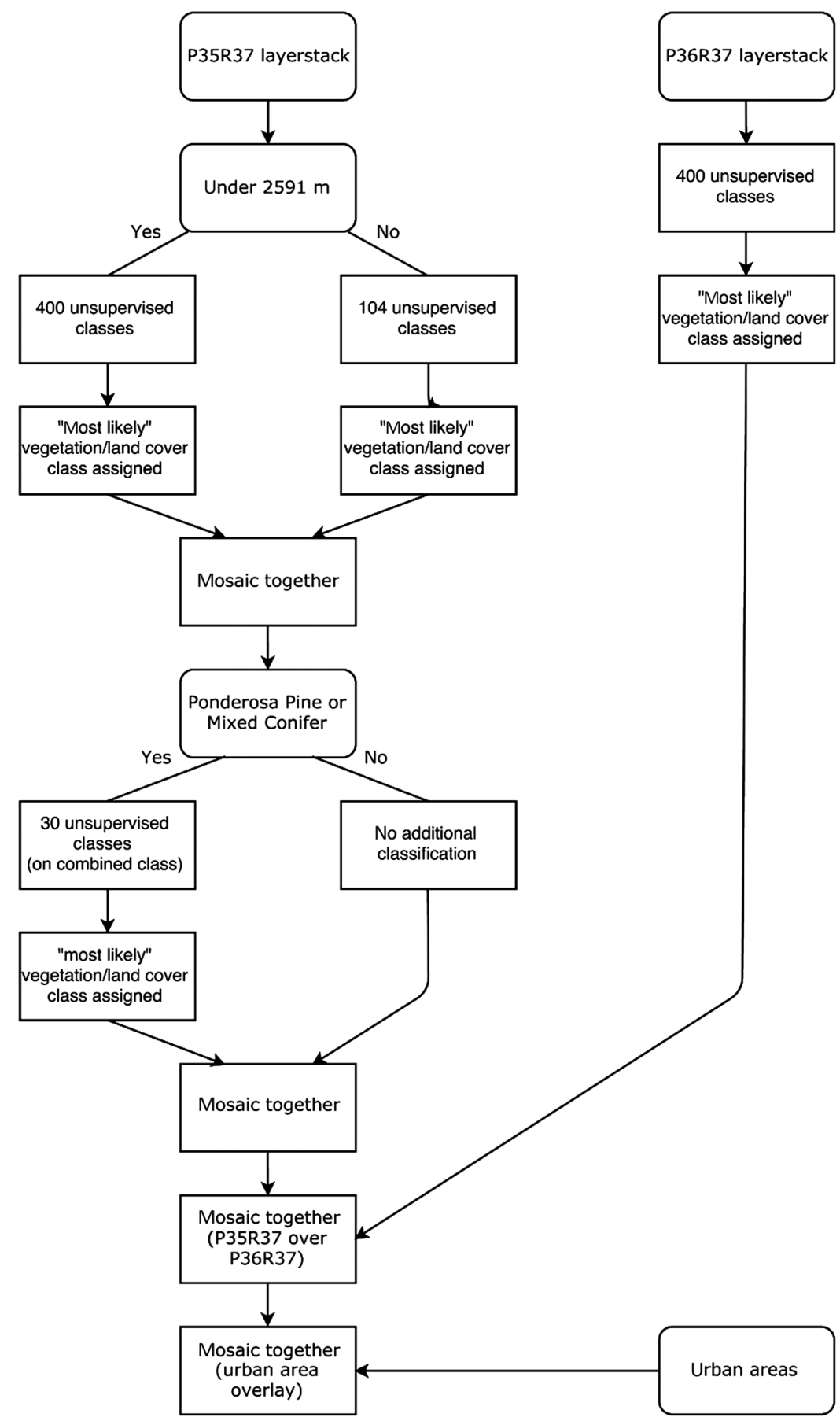

Fig. 3 Flowchart of process steps in creating the unsupervised map.

vegetation class, nor was burned vegetation removed or reassigned from the dataset. After the SWReGAP vegetation type field data were generalized into one of the 16 final classes, they were combined with the field data points from the 2017 field campaign. The field data points were then grouped into the individual vegetation class shapefiles using ArcMap (v. 10.5). They were then further subdivided by Landsat path/row. These groups of points that represented the same vegetation class (in a specific path/row) were then opened into ERDAS Imagine (v. 2014) and converted into AOI points, before being combined with the respective Landsat 8, NDVI, and DEM image layer files to create representative signature files. The six-date Landsat 8 image stack (with NDVI and DEM) discussed earlier was used to create the signature files for 
P35R37, whereas the seven-date Landsat 8 image stack (with NDVI and DEM) was used for P36R37. During the supervised classification, "minimum distance" was used as the parametric rule, whereas a nonparametric rule was not employed. Water, agriculture, Riparian Forest/ Woodland, mine, and urban were added back in from the unsupervised classification map (non $3 \times 3$ spatial filtered version). Then, a $3 \times 3$ median filter was run on the image.

\subsection{Reference Data}

Ninety-five observation sites were visited during two-field campaigns in 2017. Additionally, 933 field observation "points" in the mapping area, which were collected from 2001 to 2004, were subset from the historical SWReGAP field database. Each set of reference data are representative samples reflecting the land cover composition in the study area.

\subsubsection{7 field campaign}

The 2017 field campaign was based on a map of semirandom, accessible points in the study area that included a number of points for each of the generalized vegetation/land cover classes. Roads layers from the San Carlos Apache Reservation, Tonto and Apache-Sitgreaves National Forest, and other sources were buffered by $200 \mathrm{~m}$ in ArcMap 10.5 (ESRI 2016) to constrain the accuracy assessment points to areas near a road. The map was broken into six regions based on the distribution of major roads and land management/ownership regions. Random points were generated for each vegetation class for each region with a minimum allowed distance between points of $100 \mathrm{~m}$. Some classes, such as Spruce-Fir Forest, are less spatially extensive and therefore not represented in all regions; this resulted in 74 class/region combinations. We attempted to create 10 points in each of the 74 class/region areas; however, because of the small spatial extent of some classes as well as the minimum allowed distance constraint, this was not always possible. Eight of the 74 class/region combinations received $<10$ random sampling points. This resulted in a total of 684 possible field sampling points.

Field work was performed September 18 to 22, 2017, and October 31 to November 1, 2017, by driving along well-maintained roads to predetermined accuracy assessment points. Allowing for a suitable area to pull off, we attempted to locate the point to collect field data (Fig. 4). If a fence line (or a steep drop-off) impeded access, a "subjective point" was placed as near to the actual point as possible. Other subjective points were added along the route, often within broad expanses of a single vegetation type, or in unique vegetation "islands" within a more continuous cover. A total of 95 points were sampled. At each site, a GPS point and photographs in the four cardinal directions (north, east, south, and west) were collected and information on the local vegetative cover were documented, including the major vegetation species and their apparent abundances, and overall vegetation type based on one of the mapped vegetation classes. General vegetation of areas bordering the site was noted as well, as was evidence of fire and tree mortality/regeneration.

\subsubsection{1 to 2004 SWReGAP field campaigns}

Over the course of 2-1/2 field seasons, approximately 93,000 reference samples were collected directly, or obtained from other contemporary projects, for the SWReGAP land-cover mapping effort in the southwestern states of Arizona, Colorado, Nevada, New Mexico, and Utah. ${ }^{7}$ Of those, 933 were in the study area (Fig. 5). In the study area, the vast majority of field plots were field collected by traveling easily navigable roads and selecting plots that were at least 1 hectare in size with stand homogeneity. ${ }^{7}$ Ocular estimates included percent cover of dominant species and abiotic site characteristics. GPS coordinates were recorded.

\subsection{Accuracy Assessment}

Classification accuracy measures the agreement between what is known to be on the ground (i.e., reference condition) and the product of a remotely sensed image classification (expected condition).$^{30}$ To perform an accuracy assessment, a user compares reference data with the expected class 


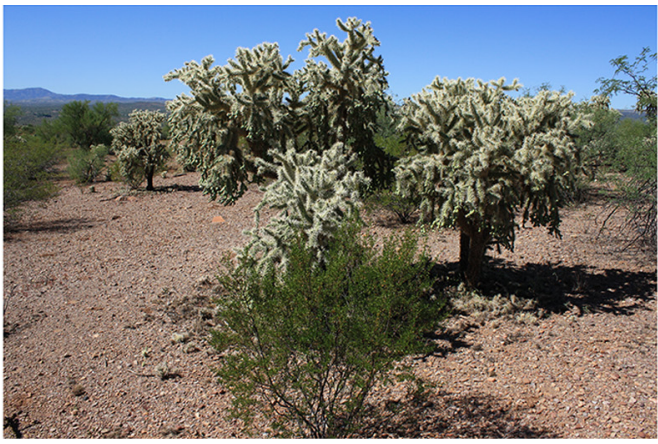

(a)

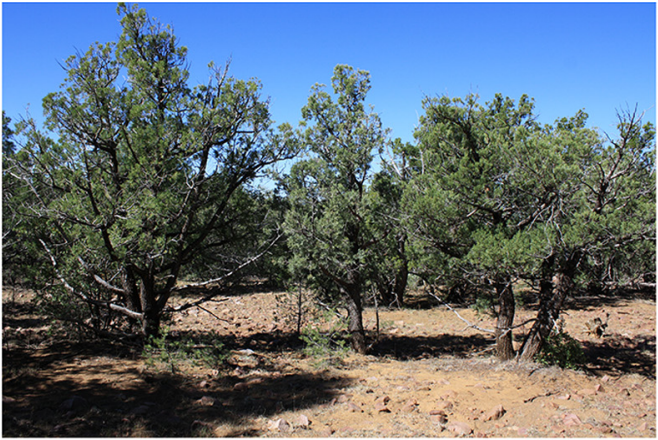

(c)

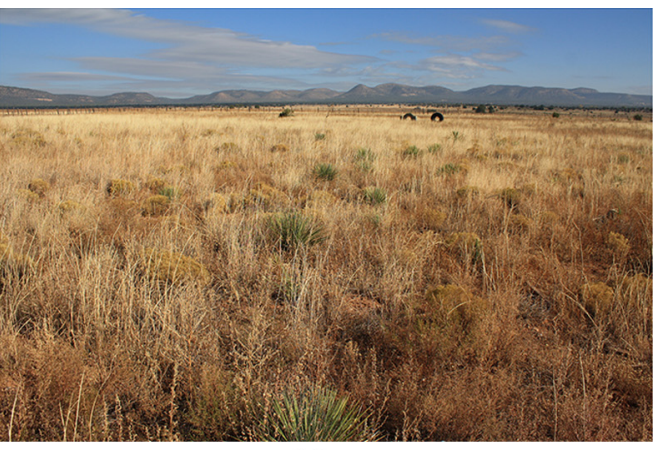

(b)

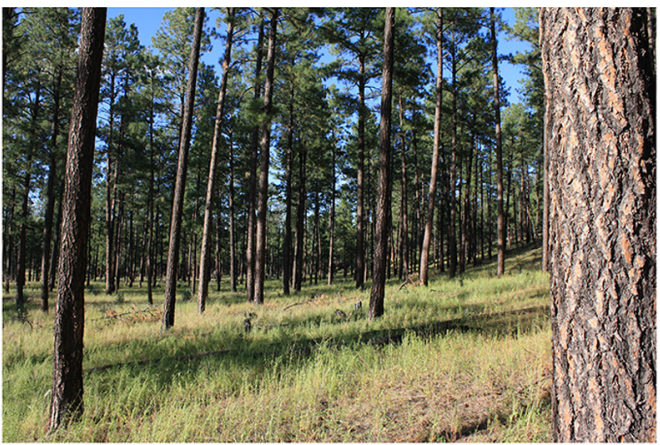

(d)

Fig. 4 Representative images of some vegetation classes from the study area: (a) Sonoran and Chihuahuan Desertscrub (Sonoran), (b) Plains and Semidesert Grassland, (c) Pinyon-JuniperOak Woodland, and (d) Ponderosa Pine Forest.

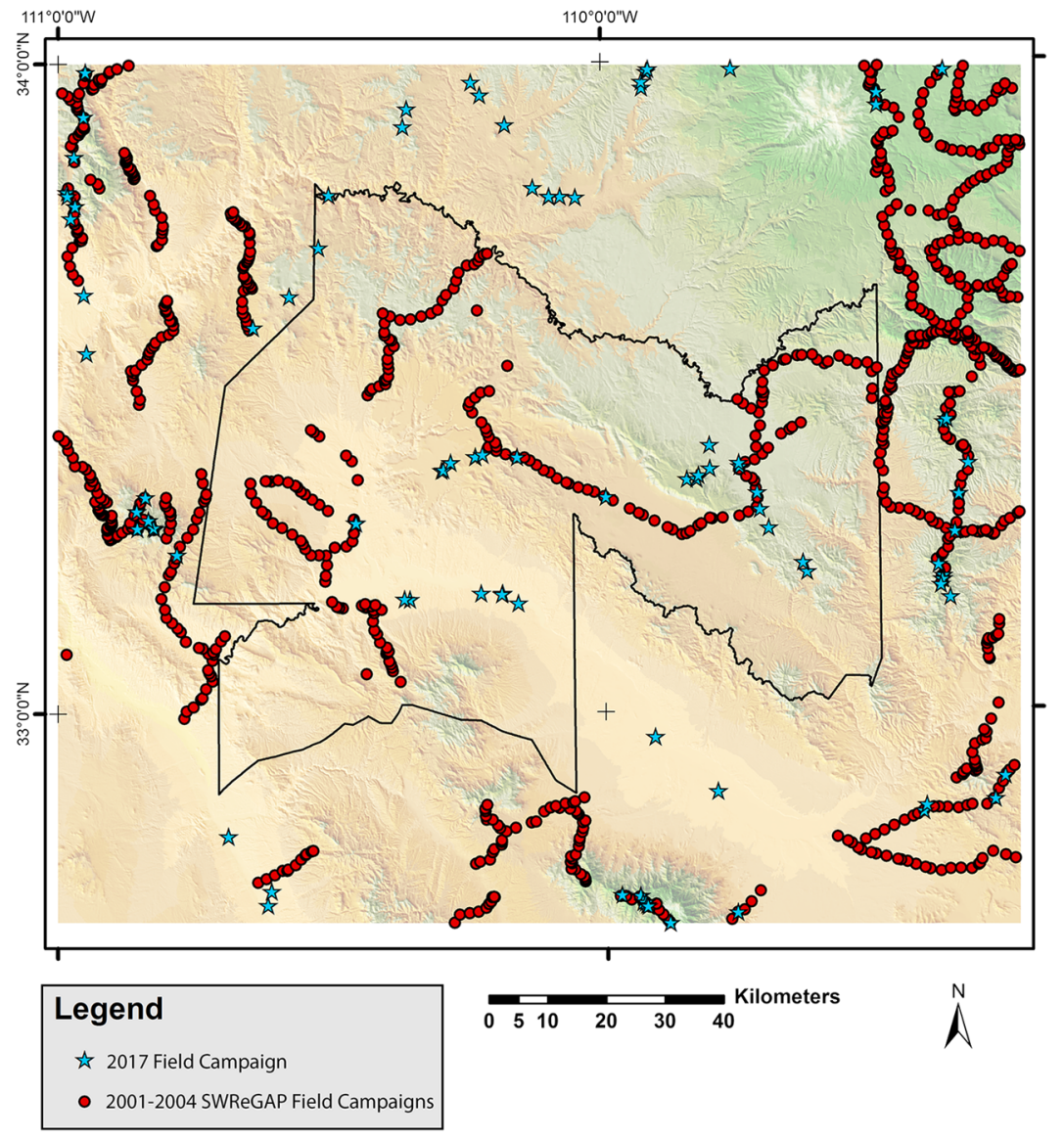

Fig. 5 Sites where vegetation and land cover field data were collected. 
at a number of locations within the image. An error matrix is developed that provides a descriptive statistical technique to determine overall accuracy. Overall accuracy is the number of pixels correctly classified divided by the total number of pixels. ${ }^{31}$ In addition, accuracies of each vegetation class can be computed, with both a "consumer's accuracy (CA)" and "producer's accuracy (PA).,"32 The CA divides the number of correctly classified pixels by the total number of pixels assigned to a class by the classification analysis (expected). The PA divides the number of pixels correctly classified per class as a percentage of the total number of pixels belonging to that class as described by the reference data. Classification errors occur via omission, when a feature is left out of the class, and via commission, when a feature is incorrectly included in a class.

\subsubsection{Statistical analysis}

The unsupervised classification map was compared with 2017 field data and SWReGAP field data. Additionally, the recoded SWReGAP map was compared with 2017 field campaign data. The SWReGAP map was also compared with the SWReGAP field data to determine an upper boundary for this map's accuracy over the study area. Finally, the supervised classification map was compared with both the SWReGAP and 2017 field campaign data to estimate upper boundaries for this map's accuracy. Accuracy assessments were developed in $\mathrm{R}^{33}$ using the caret package. ${ }^{34}$ The error matrices for the SWReGAP map to SWReGAP field data, and supervised classification are not shown as the field data (100\%) were used as the training data to produce these maps.

\section{Results}

\subsection{Maps}

Figure 6 shows the results of our mapping efforts. Figure 6(a) was created from a 904 class unsupervised classification using Landsat 8 OLI satellite and DEM data. The determination of vegetation and land cover class designations was based on reference to the SWReGAP map. Figure 6(b) was created from recoding the SWReGAP vegetation/land cover map for the study area to the same classes used in the unsupervised classification map. An additional "unclassified" class was added to capture SWReGAP vegetation and land cover classes that did not directly fit into the 16-class scheme. Figure 6(c) was created from an initial supervised classification employing training sites derived directly from the SWReGAP and 2017 field campaigns. All SWReGAP field data [specifically vegetation/land cover class (generalized) and associated GPS position] in the study area were used in the analysis, and were not checked to see if had changed (burned, changed vegetation type, etc.) in the intervening years since it was collected (2001 to 2004). In addition, all vegetation/land cover class and associated location observations in the study area from the 2017 field campaign were also utilized to create training sites in the supervised classification.

\subsection{Accuracy Assessment}

\subsubsection{Unsupervised classification}

The results of the unsupervised classification had an overall accuracy of $53 \%$ when compared with 2017 field data (Table 3). In general, CA was higher than PA. Agriculture (Ag) and PinyonJuniper-Evergreen Oak Woodland were the most accurate classes overall with both CA and PA $>0.50$. Madrean Pine-Oak Forest/Woodland was the least accurate class with both CA and PA falling below 0.25 .

The unsupervised classification map was assessed using SWReGAP field data (Table 4) and compared with the accuracy assessment using the 2017 field data. Overall accuracy was similar at $52 \%$ with mixed results in both CA and PA. Not all classes can be compared between the 2017 field data and the SWReGAP field data since the SWReGAP field data are missing any Agricultural observation points and the 2017 field data is missing Spruce-Fir Forest. All of the 
(a)

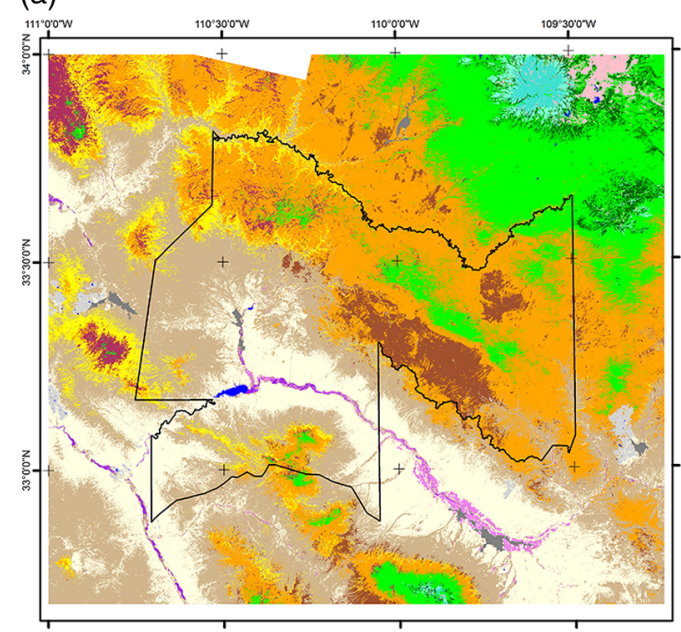

(b)

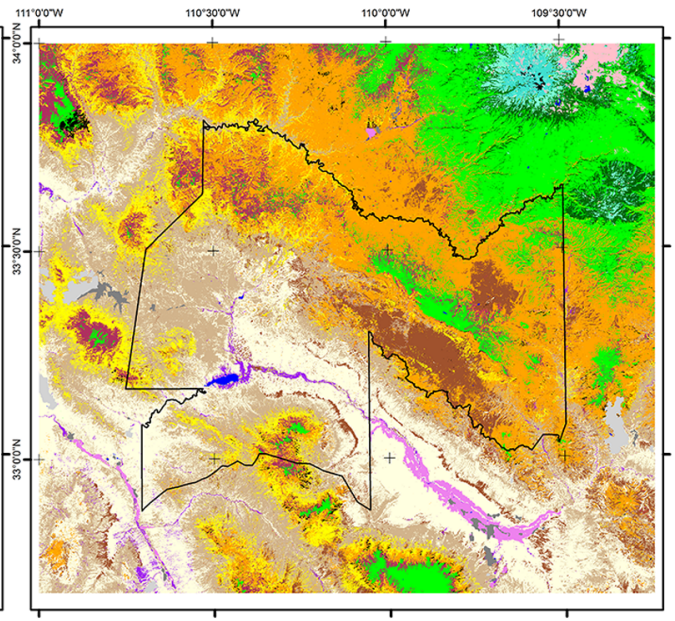

(c)
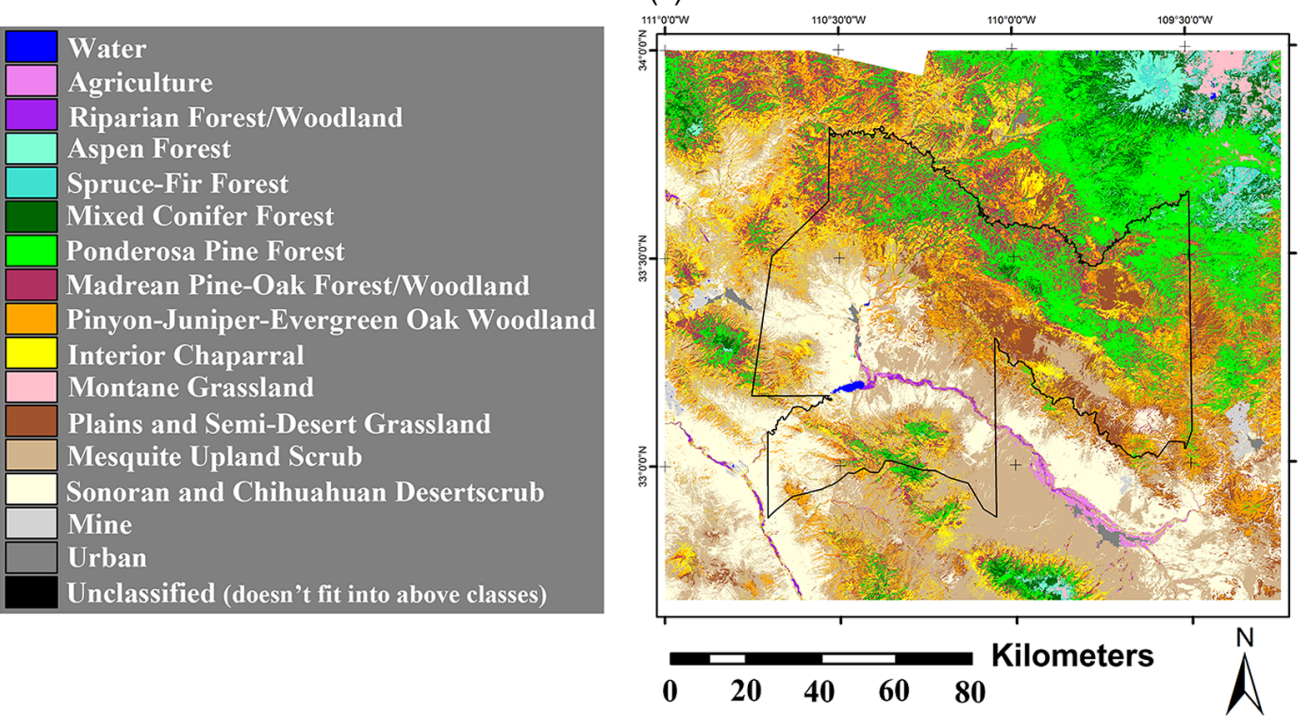

Fig. 6 (a) Unsupervised classification, (b) recoded SWReGAP map, and (c) supervised classification.

classes saw changes in either CA or PA and most classes saw changes in both. Aspen Forest and Pinyon-Juniper-Evergreen Oak Woodland were lower in both CA and PA, while Mixed Conifer Forest, Ponderosa Pine Forest, and Madrean Pine-Oak Forest/Woodland were higher in both CA and PA. Interior chaparral, Montane Grassland, and Plains/Semidesert Grassland had higher PA but lower CA. Sonoran/Chihuahuan Desertscrub had lower PA but higher CA. Riparian Forest/ Woodland and Mesquite Upland Scrub maintained their CA but had lower PA. Montane Grassland, Plains/Semidesert Grassland, and Sonoran/Chihuahuan Desertscrub were the most accurate (PA and $\mathrm{CA}>0.50$ ), whereas Spruce-Fir Forest was the least accurate (PA and $\mathrm{CA}<0.25)$.

\subsubsection{SWReGAP}

The SWReGAP map was assessed using 2017 field data (Table 5). Overall accuracy was 44\%, a reduction of 9\% from the unsupervised classification map assessed with 2017 field data with mixed results in both CA and PA. Madrean Pine-Oak Forest/Woodland was the only class to improve in both CA and PA. Aspen Forest, Ponderosa Pine Forest, Montane Grassland, and Mesquite Upland Scrub showed decreases in both CA and PA. Pinyon-Juniper-Evergreen Oak Woodland had higher CA but lower PA, whereas Interior Chaparral had lower CA but higher PA. 
Table 3 Error matrix comparing the unsupervised classification results (expected) to the 2017 field data (reference).

\begin{tabular}{|c|c|c|c|c|c|c|c|c|c|c|c|c|c|c|c|}
\hline \multicolumn{16}{|c|}{ Reference } \\
\hline & & $\mathrm{Ag}$ & Rip & Aspen & MxCon & Pondo & MPO & PJO & Chap & MG & PSDG & Mesq & Desert & Total & CA \\
\hline \multirow[t]{15}{*}{ Expected } & $\mathrm{Ag}$ & 2 & 1 & 0 & 0 & 0 & 0 & 0 & 0 & 0 & 0 & 0 & 0 & 3 & 0.67 \\
\hline & Rip & 0 & 1 & 0 & 0 & 0 & 0 & 0 & 0 & 0 & 0 & 0 & 0 & 1 & 1.00 \\
\hline & Aspen & 0 & 0 & 2 & 0 & 0 & 0 & 0 & 0 & 0 & 0 & 0 & 0 & 2 & 1.00 \\
\hline & MxCon & 0 & 0 & 1 & 1 & 0 & 0 & 0 & 0 & 1 & 0 & 0 & 0 & 3 & 0.33 \\
\hline & Pondo & 0 & 0 & 0 & 3 & 6 & 2 & 1 & 3 & 2 & 1 & 0 & 0 & 18 & 0.33 \\
\hline & MPO & 0 & 0 & 1 & 2 & 3 & 0 & 1 & 1 & 0 & 0 & 0 & 0 & 8 & 0.00 \\
\hline & PJO & 0 & 0 & 0 & 0 & 3 & 0 & 18 & 2 & 0 & 2 & 0 & 0 & 25 & 0.72 \\
\hline & Chap & 0 & 0 & 0 & 0 & 0 & 0 & 0 & 2 & 0 & 1 & 0 & 0 & 3 & 0.67 \\
\hline & $M G$ & 0 & 0 & 0 & 0 & 0 & 0 & 0 & 0 & 2 & 0 & 0 & 0 & 2 & 1.00 \\
\hline & PSDG & 0 & 0 & 0 & 0 & 0 & 0 & 1 & 0 & 0 & 5 & 0 & 0 & 6 & 0.83 \\
\hline & Mesq & 0 & 2 & 0 & 0 & 0 & 0 & 1 & 0 & 0 & 3 & 7 & 2 & 15 & 0.47 \\
\hline & Desert & 0 & 0 & 0 & 0 & 0 & 0 & 0 & 0 & 0 & 2 & 3 & 4 & 9 & 0.44 \\
\hline & Total & 2 & 4 & 4 & 6 & 12 & 2 & 22 & 8 & 5 & 14 & 10 & 6 & 95 & \\
\hline & PA & 1.00 & 0.25 & 0.50 & 0.17 & 0.50 & 0.00 & 0.82 & 0.25 & 0.40 & 0.36 & 0.70 & 0.67 & & \\
\hline & & & \multicolumn{2}{|c|}{ Overall } & 0.5263 & & & & & & appa & 0.4578 & & & \\
\hline
\end{tabular}

Both Mixed Conifer Forest and Plains/Semidesert Grassland had higher CA, whereas Riparian Forest/Woodland had higher PA. Sonoran/Chihuahuan Desertscrub had lower CA. Just as in the unsupervised classification map, agriculture and Pinyon-Juniper-Evergreen Oak Woodland were the most accurate classes, whereas Madrean Pine-Oak Forest/Woodland was the least accurate.

Lowry et al. ${ }^{7}$ reported a validation accuracy of $61 \%$ for the entire five state mapping area. This validation accuracy was based on an accuracy assessment of an intermediary product and the accuracy of the final SWReGAP map is likely higher than the validation accuracy. To find an upper boundary for accuracy of the final SWReGAP product over the study area, the SWReGAP map was compared with the SWReGAP field data. The resultant accuracy is overestimated because the test data were taken from the training data ${ }^{30}$ but it sets the upper boundary of accuracy at $75 \%$. The overall accuracy of the SWReGAP map was roughly considered to be between these boundaries (61\% minimum-measured over the five state mapping areas, and 75\% maximum-measured over the study area). The error matrix comparing the recoded SWReGAP map to the SWReGAP field data is not presented here, because $100 \%$ of the field data were used to create the map, and it does not represent a competent estimate.

\subsubsection{Supervised classification}

The results of the supervised classification had an overall accuracy of $43 \%$ when compared with 2017 field data, and 47\% when compared with the SWReGAP field data. The error matrices are not presented here, because $100 \%$ of the field data were used to create the map, and they represent an unrealistic upper limit to the accuracy estimates. Even so, the supervised classification map has very low accuracy and probably requires a significant amount of work with the selection of training sites before being useful as an accurate map product. Moreover, this classification was only meant to explore the initial results of using a supervised classification on the field data to see if that is a reasonable avenue for future mapping. 
Table 4 Error matrix comparing the unsupervised classification map (expected) to the SWReGAP field data (reference).

Reference

\begin{tabular}{|c|c|c|c|c|c|c|c|c|c|c|c|c|c|c|c|}
\hline \multicolumn{16}{|c|}{ Reference } \\
\hline & & Rip & Aspen & SprFir & MxCon & Pondo & MPO & PJO & Chap & $M G$ & PSDG & Mesq & Desert & t Total & CA \\
\hline \multirow[t]{15}{*}{ Expected } & Rip & 2 & 0 & 0 & 0 & 0 & 0 & 0 & 0 & 0 & 0 & 0 & 0 & 2 & 1.00 \\
\hline & Aspen & 0 & 5 & 1 & 5 & 0 & 0 & 0 & 0 & 0 & 0 & 0 & 0 & 11 & 0.45 \\
\hline & SprFir & 0 & 0 & 0 & 0 & 0 & 0 & 0 & 0 & 0 & 0 & 0 & 0 & 0 & NA \\
\hline & MxCon & 0 & 8 & 5 & 31 & 5 & 0 & 0 & 0 & 0 & 0 & 0 & 0 & 49 & 0.63 \\
\hline & Pondo & 9 & 7 & 12 & 56 & 73 & 9 & 5 & 1 & 8 & 0 & 0 & 0 & 180 & 0.41 \\
\hline & MPO & 3 & 1 & 1 & 3 & 0 & 26 & 0 & 2 & 0 & 0 & 0 & 0 & 36 & 0.72 \\
\hline & PJO & 13 & 0 & 0 & 2 & 6 & 37 & 72 & 16 & 0 & 11 & 9 & 5 & 171 & 0.42 \\
\hline & Chap & 1 & 0 & 0 & 0 & 0 & 18 & 3 & 31 & 0 & 0 & 4 & 1 & 58 & 0.53 \\
\hline & $M G$ & 0 & 1 & 0 & 9 & 1 & 0 & 0 & 0 & 27 & 0 & 0 & 0 & 38 & 0.71 \\
\hline & PSDG & 1 & 0 & 0 & 0 & 0 & 6 & 3 & 3 & 0 & 39 & 1 & 3 & 56 & 0.70 \\
\hline & Mesq & 9 & 0 & 0 & 0 & 0 & 3 & 8 & 35 & 0 & 15 & 99 & 40 & 209 & 0.47 \\
\hline & Desert & 5 & 0 & 0 & 0 & 0 & 0 & 0 & 0 & 0 & 5 & 36 & 77 & 123 & 0.63 \\
\hline & Total & 43 & 22 & 19 & 106 & 85 & 99 & 91 & 88 & 35 & 70 & 149 & 126 & 933 & \\
\hline & PA & 0.05 & 0.23 & 0.00 & 0.29 & 0.86 & 0.26 & 0.79 & 0.35 & 0.77 & 0.56 & 0.66 & 0.61 & & \\
\hline & & & \multicolumn{2}{|c|}{ Overall } & 0.5166 & & & & & \multicolumn{2}{|c|}{ Kappa } & 0.456 & & & \\
\hline
\end{tabular}

\section{Discussion}

The overall accuracy for each map iteration compared with the field dataset is shown in Table 6 . The unsupervised classification map ranged between $52 \%$ and $53 \%$, depending on which field dataset was used as a reference. The overall accuracy of the SWReGAP map over the study area was $44 \%$ using the 95 sites of 2017 field data as a reference. However, the SWReGAP field data are much more extensive, with nearly 10-fold more observation sites, potentially allowing for a more definitive accuracy assessment. In addition, the larger multistate SWReGAP map has an accuracy that is likely higher than the reported $61 \%$ due to their method of validation. SWReGAP validated an intermediate map developed with $80 \%$ of field data, using the remaining $20 \%$ to assess the validation accuracy. The final map was developed using $100 \%$ of the field data, and thus would be expected to be of even higher accuracy. In addition, if fewer classes were used as in the unsupervised classification map, one would expect the SWReGAP map to be of higher accuracy than the stated $61 \%$ as well. The measured $75 \%$ accuracy of the SWReGAP map using the SWReGAP field data (used to create it) sets an elevated upper limit on the accuracy of this map over the study area. Although the accuracy results are inconclusive, we deem the SWReGAP map to be more accurate in general.

Visually, the unsupervised classification map and SWReGAP map differ greatly. One geographic area of note is the Pinaleño Mountains, a large mountain range in the extreme southcentral part of the study area. This mountain range peaks at $3267 \mathrm{~m}$ in elevation, and is portrayed as covered entirely in Ponderosa Pine (green) at its middle and highest elevations on the SWReGAP map. Although Ponderosa Pine is prevalent at middle elevations, the range is actually covered in Mixed Conifer, Spruce Fir, Aspen and Montane Grassland at its highest elevations. The unsupervised classification map depicts these cover types in the Pinaleño Mountains, although they are not entirely representative of actual cover distributions. This 
Table 5 Error matrix comparing the SWREGAP map with generalized classes (expected) to the 2017 field data (reference).

Reference

Ag Rip Aspen MxCon Pondo MPO PJO Chap MG PSDG Mesq Desert Total CA

\begin{tabular}{ccccccccccccccc}
\hline Expected Ag & 2 & 0 & 0 & 0 & 0 & 0 & 0 & 0 & 0 & 0 & 1 & 0 & 3 & 0.67 \\
Rip & 0 & 1 & 0 & 0 & 0 & 0 & 0 & 0 & 0 & 0 & 0 & 0 & 1 & 1.00 \\
Aspen & 0 & 0 & 0 & 0 & 0 & 0 & 0 & 0 & 0 & 0 & 0 & 0 & 0 & NA \\
MxCon & 0 & 0 & 0 & 1 & 1 & 0 & 0 & 0 & 0 & 0 & 0 & 0 & 2 & 0.50 \\
Pondo & 0 & 0 & 3 & 5 & 3 & 0 & 3 & 2 & 4 & 1 & 0 & 0 & 21 & 0.14 \\
MPO & 0 & 0 & 0 & 0 & 5 & 1 & 2 & 2 & 0 & 1 & 0 & 0 & 11 & 0.09 \\
PJO & 0 & 0 & 0 & 0 & 3 & 0 & 16 & 1 & 0 & 1 & 0 & 0 & 21 & 0.76 \\
Chap & 0 & 0 & 0 & 0 & 0 & 1 & 0 & 3 & 0 & 0 & 1 & 0 & 5 & 0.60 \\
MG & 0 & 0 & 1 & 0 & 0 & 0 & 0 & 0 & 1 & 0 & 0 & 0 & 2 & 0.50 \\
PSDG & 0 & 0 & 0 & 0 & 0 & 0 & 0 & 0 & 0 & 5 & 0 & 0 & 5 & 1.00 \\
Mesq & 0 & 0 & 0 & 0 & 0 & 0 & 1 & 0 & 0 & 3 & 4 & 2 & 10 & 0.40 \\
Desert & 0 & 2 & 0 & 0 & 0 & 0 & 0 & 0 & 0 & 3 & 4 & 4 & 13 & 0.31 \\
Total & 2 & 3 & 4 & 6 & 12 & 2 & 22 & 8 & 5 & 14 & 10 & 6 & 94 & \\
PA & 1.00 & 0.33 & 0.00 & 0.17 & 0.25 & 0.50 & 0.73 & 0.38 & 0.20 & 0.36 & 0.40 & 0.67 & & \\
\hline \hline
\end{tabular}

Table 6 Measured overall accuracies for different vegetation/land cover maps. These values are derived from a comparison against either the 2017 field campaign or 2001 to 2004 SWReGAP field data.

\begin{tabular}{lccc}
\hline \hline & Unsupervised & Recoded SWReGAP (\%) & Supervised (\%) \\
\hline 2017 field data & $53 \%$ & 44 & $43^{\mathrm{a}}$ \\
SWReGAP field data & $52 \%$ & $75^{\mathrm{a}}$ & $47^{\mathrm{a}}$ \\
\hline \hline
\end{tabular}

${ }^{a}$ Accuracy values are artificially high as the data that were used to assess the accuracy of the supervised classification were also used to train the classification.

seems to be one small part of the study area, where the unsupervised classification map improves on the accuracy of the vegetation depiction.

During the analysis, very few "small" SWReGAP vegetation/land cover classes (those with fewer pixels in the study area associated with them) came up as "likely" classes. There may not have been enough unsupervised classes in general, and the chosen $0.001 \%$ class size threshold used in the ISODATA unsupervised classification may have been too large, or it is possible that other parameter(s) may be at fault. More unsupervised classes would have resulted in more numerous classes with fewer pixels and potentially, a greater opportunity for small SWReGAP vegetation/land cover classes to represent them. A lower class size threshold percentage in ISODATA could have worked in roughly the same way, allowing smaller classes to be generated and ultimately classified as one of the small SWReGAP classes. This is not believed to be a major issue; however, because small classes, by their definition, do not cover much land area and many (if not all) would have ultimately have been generalized into a larger class anyway.

SWReGAP classes have a higher thematic class "resolution." During the process of generalizing the SWReGAP classes to fit within the 16 classes of the unsupervised classification map, 
there were some issues that could have affected negatively the overall and individual class accuracy estimates. For instance, we feel that the fairly common SWReGAP class "Juniper Savanna" would have best been split between Pinyon-Juniper-Oak Woodland and Plains/Semidesert Grassland depending on the tree density. It was, however, assigned to Pinyon-Juniper-Oak alone.

SWReGAP field data are also significantly older (2001 to 2004 versus 2017) and there were probably some instances of change in the landscape at the field observation sites, decreasing the apparent accuracy results. Areas affected by fire in the intervening years may be extensive in some classes (Ponderosa Pine, Mixed Conifer, and Interior Chaparral, for instance), and this could have significantly skewed the results as well. The accuracy of the individual classes differed greatly and was dependent on what field dataset it was referenced to, further confusing the decision about which map is more accurate. Fire history could have also affected the accuracy of our supervised classification map causing the forest/chaparral classes to be inaccurately assigned. The fact that all of the 2001 to 2004 SWReGAP field data in the study area were used (unchanged) to create training sites and vegetation spectral signatures for the supervised classification needs to be taken into account. We expect Ponderosa Pine and Mixed Conifer in particular, and Madrean Pine-Oak, Interior Chaparral, Spruce-Fir and Aspen to have greater errors compared with other classes because those classes are susceptible to big changes from intervening fire. In this particular case, the SWReGAP training data could be suspect solely because of age, and give poor results unless it is carefully vetted and burned areas accounted for. This may also affect the accuracy numbers when compared against the SWReGAP field data (verses the 2017 field data), making the forest/chaparral classes seem less accurate.

Why the huge difference in overall accuracy measurements of the SWReGAP map using the 2017 field data (44\%) verses the 2001 to 2004 SWReGAP field data (75\%)? Despite the 75\% overall accuracy measurement being an overestimation based on it being the training data for the creation of the map itself, the overall accuracy using the 2017 field data, 44\% seems artificially low. Our only explanation is that there were far too few-field observation sites (95) to give us an accurate portrait of a map covering $24,000 \mathrm{~km}^{2}$ in such a diverse landscape. Additionally, many of these observation sites are highly spatially correlated as they are found along access roads and not randomly distributed across the mapping area, making our collection of field data less effective than even the low number reflects. The SWReGAP field data have a similar issue (albeit even more pronounced) with high spatial correlation because of the tight distribution along access roads, but the sheer number of points still allows for a better estimate of the map's accuracy.

The technique to classify the image data into many classes, and recombine them using the SWReGAP map as a guide was envisioned as a way to allow the map to differ significantly from and yet potentially improve upon the SWReGAP map. Unsupervised classification algorithms are adept at "pulling apart" the spectral variability of the image data, and minimizing the variability of the individual classes. By iteratively classifying the image into many classes, the variability of each class should be minimized, and the likelihood of it being a similar vegetation or land cover class maximized. The assignment of vegetation and land cover classes to these unsupervised classes, however, is a major potential source of error. In supervised classification, the vegetation or land cover class is usually determined for the training areas "a priori," and this class assignment is applied to the entire supervised class. The use of the SWReGAP map was expected to help account for this disadvantage.

The SWReGAP and our classification maps were done from images acquired at different times (12+ years difference), from different platforms (Landsat ETM+ and Landsat 8 OLI), classified by different procedures and analysts. To be compared, the SWReGAP map was translated into the same classification scheme and both were shown at the same level of detail. The accuracy assessment allows for quantitative comparisons of different interpretations and produces variations as described.

To expand upon this research, we consider that in addition to the comparison with the SWReGAP data, each unsupervised class could also be checked against a NDVI time plot (class average NDVI verses date) and other variables (such as elevation and class distribution) to help decide what class it most resembled. Additionally, we suggest that the supervised classification would be improved upon by checking the SWReGAP field data points to see if they were burned, or had changed class in the intervening years. It is still expected, that a more robust, and iterative supervised classification procedure could ultimately improve the map and result in an accurate 
rendition of the vegetation classes. Updating the unsupervised version could probably produce a similar result but would probably require even more time. In retrospect, we could have identified unsupervised classes that had no clear winner (where the "most likely" vegetation/land cover class had only a small edge over second place) and then analyzed the NDVI time plot and other variables to make a final determination. This hybrid option could potentially be accomplished in a reasonable amount of time.

\section{Conclusions}

Our approach to improve upon a regional, multistate mapping effort using an unsupervised classification to make updates in a smaller area was of limited success. A multitiered unsupervised classification generated over 900 classes, and these classes were then compared individually with the SWReGAP map and recoded to coincide with a class that represented the largest majority of the shared pixels. Our hypothesis was that the recombined, resultant map would update and potentially improve upon the vegetation/land cover class distributions of the SWReGAP map over the $24,000 \mathrm{~km}^{2}$ study area.

Although a slight improvement (53\% versus $44 \%$ ) was measured in the overall accuracy of the unsupervised classification map versus the SWReGAP map using the limited field data from 2017, the field data collected during the previous SWReGAP mapping effort allowed for an analysis depicting the opposite. As the SWReGAP field campaign collected 933 points over the mapping area compared with the 95 points that were visited during the much shorter 2017 field campaign, more emphasis should be put on the results of the accuracy assessment conducted with a much larger set of reference samples. Therefore, it is surmised that the SWReGAP map is more accurate overall. Just how much more accurate is unknown as the accuracy of the SWReGAP map was measured as an upper limit as the field data $(100 \%)$ was used to create the map. One would predict that the more classes generated by this multitiered, unsupervised technique, the more it should mimic the comparison SWReGAP map, but even with the $900+$ classes, it was not enough. Although errors were certainly propagated from the SWReGAP map, we accept that this experimental technique was insufficient to overcome this shortfall and added new sources of error. Future efforts to develop a new vegetation map would benefit from using a carefully selected subset of the field data collected by SWReGAP and the 2017 field campaigns as training data. It is surmised that this more traditional supervised approach, with numerous, potential training sites, has a greater chance of success in a shorter timeframe than updating the vegetation class assignments of a pre-existing map on a class-by-class basis when there are over 900 classes to analyze. Although it is likely that the vegetation class assignments for the unsupervised classification could be greatly improved upon by analyzing the NDVI time plots (phenology) and other variables, it would almost certainly require a significant amount of time because of the sheer number of classes to consider. Perhaps if the class-by-class analysis was limited in scope to cases where there was no clear winner "most likely" class, the timeconstraint issue could be overcome and the map improved to a sufficient degree.

The final conclusion is that while it is not always possible, attaining a sufficient set of field reference data points is critical, and improves analysis dramatically. If we had relied on the 95 field sites visited during the 2017 field campaign, we would have had a different finding than if using the 933 SWReGAP field sites we ultimately chose to base our conclusions on. It may have been concluded that the unsupervised classification had indeed improved on the SWReGAP map over the study area, while it had not. Ultimately, the technique used to develop this map was insufficient at producing an accurate product.

\section{Acknowledgments}

This research was conducted with support from the Land Change Science (LCS) Program in the Land Resources Mission Area of the U.S. Geological Survey (USGS). We would like to provide thanks for the cooperation and assistance provided by the San Carlos Apache Tribe, Department of Forest Resources, especially Dee Randle, Alan Rose, Irene Martinez, and Paul Buck. Partners from the US Bureau of Indian Affairs (Fort Apache Agency), Orlando Carroll, Jere McLemore, 
and Nona Tuchawena helped provide support and staff for the field campaign. We would also like to thank the White Mountain Apache Tribal Forestry, especially Robert Lacapa (with Mike and Sam), for providing assistance and guidance in accessing their lands. We would like to thank Dr. Kathryn Thomas for working with us to interpret the SWReGAP field data. We acknowledge our USGS reviewers, Dr. Christopher Soulard, Dr. Cynthia Wallace, and Dr. Miguel Villarreal for their help in revising this paper. Any use of trade, firm, or product names is for descriptive purposes only and does not imply endorsement by the U.S. Government.

\section{References}

1. S. W. Running et al., "A remote sensing based vegetation classification logic for global land cover analysis," Remote Sens. Environ. 51, 39-48 (1995).

2. Y. Xie, Z. Sha, and M. Yu, "Remote sensing imagery in vegetation mapping: a review," J. Plant Ecol. 1, 9-23 (2008).

3. C. E. Woodcock and A. H. Strahler, "The factor of scale in remote sensing," Remote Sens. Environ. 21, 311-332 (1987).

4. J. A. Richards, Remote Sensing Digital Image Analysis, 3rd ed., Springer, Berlin, Germany (1999).

5. J. F. Knight et al., "Regional scale land cover characterization using MODIS-NDVI $250 \mathrm{~m}$ multi-temporal imagery: a phenology-based approach," GIScience Remote Sens. 43, 1-23 (2006).

6. M. D. Jennings, “Gap analysis: concepts, methods, and recent results," Landscape Ecol. 15, 5-20 (2000).

7. J. Lowry et al., "Mapping moderate-scale land-cover over very large geographic areas within a collaborative framework: a case study of the Southwest Regional Gap Analysis Project (SWReGAP)," Remote Sens. Environ. 108, 59-73 (2007).

8. P. Comer et al., Ecological Systems of the United States: A Working Classification of US Terrestrial Systems, NatureServe, Arlington Virginia (2003).

9. NatureServe, NatureServe Explorer: An Online Encyclopedia of Life, NatureServe, Arlington, Virginia (2008).

10. D. H. Grossman et al., International Classification of Ecological Communities: Terrestrial Vegetation of the United States. Volume I, The National Vegetation Classification System: Development, Status, and Applications, The Nature Conservancy, Arlington, Virginia (1998).

11. C. S. A. Wallace, M. L. Villarreal, and L. M. Norman, "Development of a high-resolution binational vegetation map of the Santa Cruz river riparian corridor and surrounding watershed, Southern Arizona and Northern Sonora, Mexico," Open-File Report, no. 2011-1143, p. 22, US Geological Survey (2011).

12. U.S. Geological Survey, "Landsat-earth observation satellites," U.S. Geological Survey Fact Sheet 2015-3081, p. 4 (2015).

13. P. Li, L. Jiang, and Z. Feng, "Cross-comparison of vegetation indices derived from Landsat7 enhanced thematic mapper plus (ETM+) and Landsat-8 operational land imager (OLI) sensors," Remote Sens. 6, 310-329 (2014).

14. D. P. Roy et al., "Landsat-8: science and product vision for terrestrial global change research," Remote Sens. Environ. 145, 154-172 (2014).

15. N. R. Wilson and L. M. Norman, "Analysis of vegetation recovery surrounding a restored wetland using the normalized difference infrared index (NDII) and normalized difference vegetation index (NDVI)," Int. J. Remote Sens. 39, 3243-3274 (2018).

16. D. Randall, Personal Communication (2016).

17. S. Tuttle, The San Carlos Apache Reservation and Extension Programs, p. 4, College of Agriculture and Life Sciences, University of Arizona, Tucson, Arizona (2008).

18. R. Petrakis et al., "Vegetative response to water availability on the San Carlos Apache Reservation," For. Ecol. Manage. 378, 14-23 (2016).

19. R. E. Petrakis et al., "Evaluating and monitoring forest fuel treatments using remote sensing applications in Arizona, U.S.A.," For. Ecol. Manage. 413, 48-61 (2018).

20. S. Pilsk, Personal Communication (2012). 
21. "USGS EROS land satellite data systems (LSDS) project," LSDS Science Research and Development (LSRD), https://espa.cr.usgs.gov (2017).

22. J. Barsi et al., "The spectral response of the Landsat-8 operational land imager," Remote Sens. 6, 10232-10251 (2014).

23. C. J. Tucker, "Red and photographic infrared linear combinations for monitoring vegetation," Remote Sens. Environ. 8, 127-150 (1979).

24. A. R. Huete and R. D. Jackson, "Suitability of spectral indices for evaluating vegetation characteristics on arid rangelands," Remote Sens. Environ. 23, 213-232 (1987).

25. J. Duncan et al., "Assessing the relationship between spectral vegetation indices and shrub cover in the Jornada Basin, New Mexico," Int. J. Remote Sens. 14, 3395-3416 (1993).

26. L. M. Norman et al., "Remote sensing analysis of riparian vegetation response to desert marsh restoration in the Mexican Highlands," Ecol. Eng. 70, 241-254 (2014).

27. J. Franklin, "Predictive vegetation mapping: geographic modelling of biospatial patterns in relation to environmental gradients," Prog. Phys. Geogr. 19, 474-499 (1995).

28. "USGS The National Map," National Elevation Dataset (NED), https://nationalmap.gov/ elevation.html (2018).

29. "U.S. Census Bureau," Cartographic Boundary Shapefiles-Urban Areas, https://www. census.gov/geo/maps-data/data/cbf/cbf_ua.html (2018).

30. R. G. Congalton, "A review of assessing the accuracy of classifications of remotely sensed data," Remote Sens. Environ. 37, 35-46 (1991).

31. M. Story and R. G. Congalton, "Accuracy assessment: a user's perspective," Photogramm. Eng. Remote Sens. 52, 397-399 (1986).

32. L. L. F. Janssen and F. J. M. van der Wel, "Accuracy assessment of satellite derived landcover data: a review," Photogramm. Eng. Remote Sens. 60, 410-432 (1994).

33. R Core Team, "R: a language and environment for statistical computing," 2017, https://www .R-project.org/.

34. M. Kuhn, "Building predictive models in R using the caret package," J. Stat. Software 28, $1-26$ (2008).

Laura M. Norman is a supervisory research physical scientist at the USGS, where she has worked since 1998. Over the past 20 years, she has focused on characterizing trade-offs between management actions using complex geospatial hydrological, hydraulic, and LULC models. She has published over 50 peer-reviewed journal articles and various conference papers on a widerange of topics including watershed hydrology, environmental health, cross-border policy, regional planning, remote sensing analyses, ecosystem services, and restoration design.

Barry R. Middleton received his degree in geography from New Mexico State University. He has worked as a geographer for the USGS Western Geographic Science Center for 14 years, and specializes in remote sensing of arid and semiarid lands of the southwestern U.S. Previously, he was involved in the GAP land cover mapping for the state of New Mexico.

Natalie R. Wilson has been a scientist with the USGS since 2014. Her broad interests include vegetation community dynamics, arid lands ecology and arid lands conservation, while her current research focuses on using remote sensing, GIS technology, and ecological field techniques to study vegetation response to watershed restoration in southeastern Arizona. Her education includes her MS degree in geographic information systems technology from the University of Arizona and her BS degree in zoology from Texas A\&M University. 